\title{
Technique for inducing Botrytis squamosa sclerotium formation in vitro
}

\author{
Leandro Luiz Marcuzzo ${ }^{1}$, Aline Nascimento ${ }^{1}$, Bruna Kotkoski ${ }^{1}$
}

${ }^{1}$ Instituto Federal Catarinense - IFC/Campus Rio do Sul, CP 441, CEP 89.163-356, Rio do Sul, SC, e-mail: leandro.marcuzzo@ifc.edu.br Autor para correspondência: Leandro Luiz Marcuzzo (leandro.marcuzzo@ifc.edu.br)

Data de chegada: 28/04/2017. Aceito para publicação em: 07/06/2017.

$10.1590 / 0100-5405 / 179155$

Botrytis squamosa (Walker) is the etiological agent of Botrytis leaf blight of onion, characterized as the main leaf disease in the seedling stage of the crop. One of the primary inoculum sources of this pathogen is the sclerotium. Studies related to the survival and epidemiology of the primary inoculum of this disease require the purified organism and expressive sclerotium formation. The technique was developed at Instituto Federal Catarinense-IFC/Rio do Sul Campus with $B$. squamosa isolate obtained from mycelium plus conidia collected from injured leaf tissue of onion seedlings and multiplied for seven days at $25^{\circ} \mathrm{C}$, without light, on Petri dish containing PDA (Potato-DextroseAgar) culture medium. After this period, conidia were removed from the mycelial growth by washing with sterile water. Using a hand spray, $2 \mathrm{~mL}$ of the $1 \times 10^{5}$ conidia/mL suspension was sprayed into glass Petri dishes $(90 \times 15 \mathrm{~mm})$ containing $20 \mathrm{~mL}$ distilled water and 2 grams of around $1 \mathrm{~cm}$-long fragments of dry onion leaf straw previously autoclaved at $121^{\circ} \mathrm{C}$ for 25 minutes (Figure 1A). After inoculation, the Petri dishes were incubated in germination chambers of B.O.D (Biological Oxygen Demand) type for two weeks, at $20^{\circ} \mathrm{C}$, without light. Following this time, the fragments were withdrawn from the Petri dish and placed in a $300 \mathrm{~mL}$ glass stopper lid containing half the volume of water. After successive manual agitations, the fragments were torn and the sclerotia detached from the fragments. Then, sclerotia and fragments were placed on a plastic sieve which, under running water, was rubbed with the finger to remove fragments that could still be attached to the sclerotia. The sclerotia were removed from the sieve with the aid of forceps and placed in a Petri dish with an open lid for natural drying and subsequent storage at room temperature $\left(25^{\circ} \mathrm{C} \pm 2\right)$. The technique produces on average 200 sclerotia per Petri dish and their formation starts from the first week and stabilizes at 15 days of incubation (Figure 1B). The morphological characteristics of the sclerotia produced by this technique resemble those of sclerotia produced by the plant under field condition. This methodology has been used for the production of sclerotia employed in epidemiological studies with the pathogen at IFC/Rio do Sul Campus. This in vitro technique using tissue from the host plant can be evaluated for sclerotia induction in other Botrytis species.
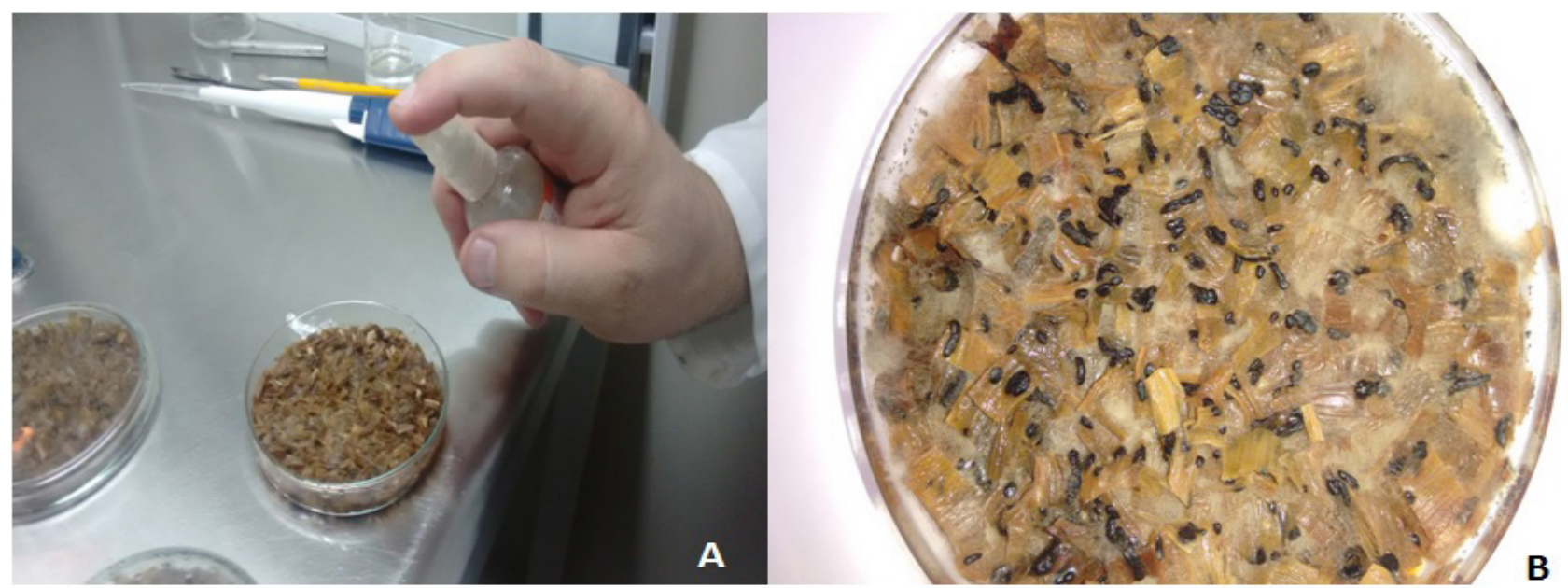

Figure 1. Inoculation of B. squamosa in straw fragments of onion leaves (A) and sclerotium formation after fifteen days of incubation (B). 